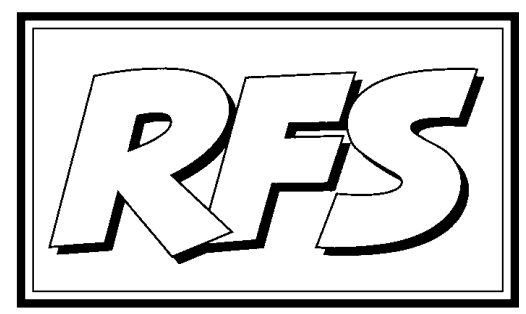

Revista de Fomento Social, 55 (2000), 595-614

\title{
El servicio de la fe y la promoción de la justicia en la educación universitaria de la Compañía de J esús de Estados Unidos
}

(Discurso en la Universidad de Santa Clara, Estados Unidos-octubre 2000)

Peter-Hans KOLVENBACH SJ

Prepósito General de la Compañía de J esús

\section{Introducción}

Esta Conferencia sobre el compromiso con la justicia en la Educación Superior de la Compañía de Jesús de Estados Unidos llega en un momento importante de la tan rica historia de las veintiocho Universidades y Centros de Estudios Superiores* representados aquí esta tarde. Hoy nos unimos también a la celebración de los 150 años de la fundación de la Universidad de Santa Clara.

* La expresión Universidades y Centros de Estudios Superiores de la Compañía se emplea para traducir el inglés J esuit Colleges and Universities (nota de los traductores). 
Tan significativo como el momento histórico, lo es también nuestra situación espacial. El Valle de Santa Clara, cuyo nombre viene del templo de la misión situado en el corazón del campus, es conocido en todo el mundo como Silicon Valley, la cuna del microchip. Ciertamente que cuando el P. Nobili, fundador de esta universidad, contempló las ruinas de la iglesia y del conjunto de edificios de la antigua misión franciscana, nunca hubiera podido soñar con que este valle se convertiría en el centro de una revolución tecnológica de alcance planetario.

Esta yuxtaposición de misión y microchip es expresiva detodos los centros educativos de la Compañía. Fundados originalmente para servir a las necesidades educativas y religiosas de las poblaciones de pobres inmigrantes, han llegado a ser instituciones de enseñanza altamente sofisticadas, completamente rodeadas de un mundo de riqueza, poder y cultura de un alcance global. El cambio de milenio las sorprende en toda su diversidad: son mayores, están mucho mejor equipadas, son más complejas y profesionales que nunca; y además están más preocupadas por su identidad católica y jesuita.

En la historia de la educación superior de la Compañía en América, hay mucho que agradecer, en primer lugar a Dios y a la Iglesia, pero sin duda también a los muchos profesores, estudiantes, personal de administración y bienhechores que han logrado hacer de ella lo que hoy es. Pero esta conferencia les reúne a Vds. de lo ancho y largo de los EEUU con invitados de universidades jesuitas de otras partes, no para congratularnos unos a otros, sino con una intención estratégica. En nombre de las complejas, profesionales y pluralistas instituciones que representan, están $\mathrm{Vds}$. aquí para afrontar una cuestión tan difícil como central: ¿cómo pueden expresar las Universidades y Centros de Estudios Superiores de la Compañía en Ios EEUU su preocupación por la justicia que brota de la fe, en lo que son en cuanto centros académicos cristianos de enseñanza superior, en lo que hace su profesorado, y en lo que lleguen a ser sus estudiantes?

Como una contribución a su respuesta yo quisiera (I) reflexionar con Vds. sobre lo que la fe y la justicia han significado para los jesuitas desde 1975, y después (II) prestar atención a las circunstancias concretas de hoy día, (III) sugerir lo que una justicia enraizada en la fe puede significar en la educación jesuita superior de América y (IV) concluir con una agenda para el primer decenio de los años 2000. 


\section{El compromiso jesuita con la fe y la justicia, novedad de $\mathbf{1 9 7 5}$}

Empiezo recordando otro aniversario que esta conferencia también conmemora. Hace 25 años, 10 años después de la clausura del Concilio Vaticano II, se reunían los delegados jesuitas de toda la Compañía en la Congregación General (CG) 32 para considerar cómo estaba respondiendo la Compañía de Jesús a la profunda transformación de la vida de toda la Iglesia, iniciada y promovida por el Vaticano II.

Después de mucha oración y deliberación, la Congregación fue cayendo en la cuenta lentamente de que toda la Compañía de Jesús, en todos sus muchos ministerios, estaba siendo llevada por el Espíritu de Dios a tomar una orientación nueva. El fin principal de la Compañía de J esús, el servicio de la fe, debía incluir también la promoción de la justicia. Esta nueva orientación no era sólo para aquellos que trabajaban ya con los pobres y marginados, en lo que se llamaba el apostolado social. Más bien, este compromiso tenía que ser una preocupación de toda nuestra vida y constituir una dimensión de todas nuestras tareas a postólicas ${ }^{1}$. Esta unión de la fe y de la justicia era tan central a la misión de toda la Compañía que se habría de convertir en el factor integrador de todos los ministerios ${ }^{2}$ de la Compañía; a esta luz se debería prestar particular atención a la evaluación de todos los ministerios, incluyendo las instituciones educativas 3 .

Yo mismo asistí a la CG 32, representando a la Provincia del Próximo Oriente, donde, durante siglos, la actividad apostólica de los jesuitas se había centrado en la educación, en una famosa universidad y en algunos colegios notables. Por supuesto que algunos jesuitas trabajaban en pueblos muy pobres, en campos de refugiados o en cárceles, y que otros luchaban a favor de los derechos de los trabajadores, inmigrantes y extranjeros; pero esto no siempre se consideraba un trabajo nuclear o típico de jesuitas. Nosotros, en Beirut, éramos muy conscientes que nuestra facultad de medicina, con muy santos jesuitas al frente, estaba produciendo, al menos en aquel tiempo, algunos de los ciudadanos más corruptos de la ciudad, pero ya contábamos con ello. La atmósfera social explosiva del Próximo Oriente no permitía una lucha contra las estructuras injustas y pecadoras. La liberación de Palestina era la cuestión social más importante. Las iglesias cristianas se habían

1 CG 32, D. 4, no 47.

2 CG 32, D. 2, no 9.

3 CG 32, D. 2, n. 9 y D. 4, № 76. 
embarcado en muchas obras asistenciales, pero el compromiso por la promoción de la justicia hubiera supuesto que se las asociase con los movimientos de izquierda o con el desorden político.

La situación que describo del Próximo Oriente no era excepcional en la Compañía universal de aquel tiempo. No era yo el único delegado que ignoraba las cuestiones sobre justicia o injusticia. El Sínodo de Obispos de 1971 había declarado proféticamente que la acción en favor de la justicia y la participación en la transformación del mundo se nos presenta claramente como una dimensión constitutiva de la predicación del evangelio, es decir, de la misión de la Iglesia en favor de la redención de la humanidad y la liberación de toda situación opresiva ${ }^{4}$. Sin embargo, pocos de nosotros sabíamos lo que esto significaba en nuestras circunstancias concretas.

Ya antes, en 1966, el Padre Arrupe había llamado la atención de los provinciales de América Latina sobre cómo la situación socioeconómica de todo aquel continente contradecía al Evangelio: de aquí se sigue -decía- la obligación moral de la Compañía de repensar todos sus ministerios y apostolados y de analizar si realmente responden a los requisitos de la urgencia y prevalencia de la justicia y aun de la equidad social 5 . Muchos de nosotros no alcanzamos a ver el alcance de este mensaje en nuestra situación concreta. Pero ruego se fijen en que el Padre Arrupe no pedía la supresión del apostolado de la educación en favor de la actividad social. Al contrario, afirmaba que incluso un a postolado tan sinceramente querido por la Compañía y de cuya trascendencia nadie duda, como es la educación en sus distintos niveles, debe ser sometido a reflexión en su forma concreta actual a la luz de las exigencias del problema social ${ }^{6}$.

Quizás la incomprensión o la resistencia de algunos de nosotros, los delegados, fue una de las razones por las que la CG 32 tomó finalmente una postura radical. Con una pasión tan inspiradora como desconcertante, la CG acuñó la fórmula el servicio de la fe y la promoción de la justicia, y la utilizó inteligentemente para impulsar a que toda obra jesuita y todo jesuita en particular hiciera una opción que dejaba poca escapatoria a los de corazón cobarde. Muchos, dentro y fuera de la Compañía, se sintieron indignados con

4 Sínodo Universal de Obispos 1971, Justicia en el mundo.

5 Pedro Arrupe (1966), Sobre el apostolado social en América Latina, 12 diciembre, Cf. Acta Romana XIV, 791.

6 Ibid. 
la promoción de la justicia. Como el Padre Arrupe percibió acertadamente, sus jesuitas estaban entrando, como colectivo, en un camino más duro de la cruz, que indefectiblemente llevaría consigo incomprensiones y hasta oposición de parte de las autoridades civiles y eclesiásticas, de muchos buenos amigos y de algunos de nuestros propios compañeros. Hoy, veinticinco años más tarde, esta opción se ha convertido en elemento integrante de nuestra identidad jesuita, de la conciencia de nuestra misión y de nuestra imagen pública, tanto en la Iglesia como en la sociedad ${ }^{7}$.

La expresión resumen -servicio de la fe y promoción de la justicia- tiene todas las características de un eslogan con capacidad para conquistar el mundo, que usa un mínimo de palabras para inspirar una visión dinámica de grandes dimensiones, pero con el peligro inherente de la ambigüedad. Examinemos primero el servicio de la fe, después la promoción de la justicia.

\section{A. El servicio de la fe}

Desde nuestros orígenes en 1540, la Compañía recibió el encargo solemne y oficial de la defensa y propagación de la fe. En 1975 la Congregación reafirmó que, para nosotros jesuitas, la defensa y propagación de la fe es una cuestión de vida o muerte, aun cuando las mismas palabras puedan cambiar. Fiel al Concilio Vaticano, la Congregación quiso que nuestra predicación y enseñanza tuviese como meta, no hacer prosélitos ni imponer nuestra religión a otros, sino más bien presentar, con un espíritu de amor hacia todos, a J esús y su mensaje del Reino de Dios.

Precisamente cuando el Vaticano había abandonado el nombre Propaganda Fidei, la CG 32, pasaba de la propagación al servicio de la fe. En el Decreto 4, la Congregación utilizó la expresión, que a mi me gusta más, de proclamación de la fe ${ }^{8}$. Sin embargo, en el contexto de siglos de espiritualidad jesuita, el servicio de la fe no puede significar otra cosa que llevar a nuestro mundo el don contracultural de Cristo ${ }^{9}$.

Pero ¿por qué el servicio de la fe? La misma Congregación responde a esta

7 Cf. Peter-Hans Kolvenbach (2000), Sobre el apostolado social, enero, № 3.

8 La evangelización es proclamación de la fe que actúa en el amor de los hombres ( Gal 5,6; Ef 4,15): no puede realizarse verdaderamente sin promoción de la justicia. (CG 32, D.4, no 28).

9 Cf. CG 34, D. 26, no 5. 
pregunta utilizando la expresión griega diakonía fidei ${ }^{10}$. Con ella se refiere a Cristo el Siervo sufriente que lleva a cabo su diakonia en un servicio total a su Padre hasta dar la vida por la salvación de todos. Por lo tanto, para un jesuita, no sería adecuada una respuesta cualquiera a las necesidades de los hombres y mujeres de hoy. La iniciativa debe venir del Señor que labora en los acontecimientos y en las personas aquí y ahora. Dios nos invita a unirnos a Cristo en sus trabajos, con sus condiciones y a su manera ${ }^{11}$.

Pienso que nosotros, los delegados de la CG 32, no éramos conscientes de las dimensiones teo lógicas y éticas de la misión de servicio propia de Cristo. Si hubiésemos prestado más atención a la diakonia fidei, quizá hubiésemos evitado algunos malentendidos provocados por la expresión promoción de la justicia.

\section{B. La promoción de la justicia}

Esta expresión es difícil de traducir a muchas lenguas. Los delegados estábamos familiarizados con el departamento de promoción de ventas de unos almacenes o con la promoción de amigos o enemigos a un puesto 0 cargo más elevado; pero no nos sonaba nada eso de promoción de la justicia. Para ser justos, hay que recordar que una Congregación General no es una academia científica bien dotada para distinguir y definir, para clarificar y clasificar. Frente a necesidades apostólicas radicalmente nuevas, optó por inspirar, enseñar y aun profetizar. En su deseo de ser más incisiva en la promoción de la justicia, la Congregación evitó términos tradicionales -como caridad, misericordia o amor-, ya pasados de moda en 1975. Tampoco satisfacía filantropía, ni siquiera desarrollo. La Congregación prefirió utilizar la palabra promoción con su connotación de estrategia bien planificada para hacer al mundo justo.

Ya que San Ignacio quería que el amor se expresará no solo en palabras sino en hechos, la Congregación comprometió a la Compañía en la promoción de la justicia como una respuesta concreta, radical y adecuada a un mundo que sufría injustamente. Fomentar la virtud de la justicia en los individuos no bastaba. Sólo una justicia sustantiva podía producir los cambios de actitudes y de estructuras que se precisaban para eliminar las

10 En castellano servicio de la fe [ Nota de los traductores]. Por ejemplo, CG 32, D. 11, no 13.

11 CG 34, D. 26, no 8 . 
injusticias pecadoras y o presivas que son un escándalo contra la humanidad y contra Dios.

Esta clase de justicia requiere un compromiso orientado a la acción en favor del pobre desde una valiente opción personal. Esta expresión relativamente suave, promoción de la justicia, sonaba en los oídos de algunos a lenguaje revolucionario, subversivo e incluso violento. Por ejemplo, no hace mucho tiempo el Departamento de Estado Norteamericano acusó a algunos jesuitas colombianos de ser fundadores - con mentalidad marxista- de un movimiento guerrillero. Cuando se pidieron explicaciones al Gobierno americano, se limitó a excusarse por este error, lo que mostraba que algún mensaje de este tipo le había llegado.

Así como en la diakonia fidei la palabra fe no está definida, también queda ambiguo el término justicia al hablar de promoción de la justicia. La Congregación 32 no habría aprobado el Decreto 4 si la justicia socioeconómica hubiese sido excluida, pero tampoco si no se hubiera incluido la justicia del Evangelio. Una postura casi ideológica en favor de la justicia social y, simultáneamente, una opción fuerte por la justicia evangélica que es como un sacramento del amor y la misericordia de Dios ${ }^{12}$, eran ambas indispensables. Al negarse a clarificar la relación entre las dos, la CG 32 mantuvo su radicalidad, limitándose a yuxtaponer diakonia fidei y promoción de la justicia.

En otros Decretos de la misma Congregación, cuando las dos dimensiones de la única misión de la Compañía se colocaban juntas, algunos delegados intentaron lograr una expresión más integrada, proponiendo enmiendas como el servicio de la fe a través de o en la promoción de la justicia. Expresiones así podían reflejar mejor la identificación que hacía el Sínodo de 1971 de la acción a favor de la justicia y la participación en la transformación del mundo como una dimensión constitutiva de la predicación del evangelio ${ }^{13}$. Pero se puede comprender el temor de la Congregación de que un tratamiento demasiado preciso o matizado pudiera debilitar la llamada profética o aguar el cambio radical en nuestra misión.

Mirando hacia atrás, esta simple yuxtaposición llevó a veces a una lectura truncada, parcial o desequilibrada del Decreto $4^{14}$, subrayando unilateralmen-

12 CG 33, D.1, no 32.

13 Sinodo Universal de Obispos (1971), Justicia en el Mundo.

14 Pedro Arrupe (1981), Arraigados y cimentados en la caridad, 6 febrero, no 67. Cf. Acta Romana XVIII, 465. 
te un aspecto de esta misión en detrimento de otro ${ }^{15}$, considerando la fe y la justicia como alternativas o como rivales en el apostolado. Dogmatismos o ideologías nos han llevado a veces a tratarnos más como adversarios que como compañeros. La promoción de la justicia ha quedado a veces separada de su auténtica fuente, la fe ${ }^{16}$.

De un lado, la dimensión de fe se daba por supuesta y quedaba implícita, como si nuestra identidad de jesuitas fuese suficiente. Otros, en cambio, se lanzaron precipitadamente a la promoción de la justicia sin mucho análisis o reflexión y con referencias sólo ocasionales a la justicia del Evangelio. Estos parecían que relegaban el servicio de la fe a un pasado condenado a morir. Mientras tanto, aquéllos se aferraban a un cierto estilo de fe y de Iglesia: daban la impresión de que la gracia de Dios sólo tenía que ver con la vida futura y que la reconciliación divina no llevaba consigo ninguna obligación de poner en orden las cosas de aquí en la tierra.

En este diagnóstico sincero he empleado, no tanto mis propias palabras como las de las Congregaciones siguientes, para compartir con Vds. el arrepentimiento de to da la Compañía por todas las deformaciones o excesos ocurridos y para mostrar cómo, a lo largo de los últimos veinticinco años, el Señor nos ha estado enseñando pacientemente a servir a la fe que obra la justicia de una manera más integrada.

\section{El ministerio de la educación}

Inmersos en afirmaciones radicales e interpretaciones unilaterales a propósito del Decreto 4, muchos cuestionaron si debíamos continuar manteniendo grandes instituciones educativas. Insinuaban, si es que no afirmaban, que el trabajo social directo entre los pobres y el tomar parte en sus movimientos debía ser prioritario. Hoy día, sin embargo, el valor del apostolado de la educación es reconocido de forma generalizada, y es el sector al que se dedica mayor cantidad de jesuitas y de recursos de la Compañía, siempre con la condición de que transforme sus metas, contenidos y métodos.

Ya antes de la CG 32, el Padre Arrupe había perfilado el significado de la diakonia fidei en el apostolado de la educación cuando, en el Congreso Europeo de Antiguos Alumnos de 1973, dijo:

15 CG 33, D.1, no 33 .

16 CG 34, D.3, №2.

\section{RFS}


Nuestra meta y objetivo educativo es formar hombres que no vivan para sí mismos, sino para Dios y su Cristo, para aquel que por nosotros murió y resucitó; hombres para los demás, es decir, hombres que no conciban el amor a Dios sin amor al hombre; un amor eficaz que tiene como primer postulado la justicia y que es la única garantía de que nuestro amor a Dios no es una farsa ${ }^{17}$.

El discurso de mi predecesor no fue bien recibido por muchos antiguos alumnos del encuentro de Valencia, pero la expresión hombres y mujeres para los demás ayudó realmente a que la instituciones educativas de la Compañía se planteasen cuestiones serias que les llevaron a su transformación ${ }^{18}$.

El P. Ignacio Ellacuría, en su discurso en 1982, en la Universidad de Santa Clara, expresó elocuentemente su convencimiento en favor de la promoción de la justicia en el apostolado de la educación:

Una universidad cristiana tiene que tener en cuenta la preferencia del evangelio por el pobre. Esto no significa que sean los más pobres los que deban entrar a cursar sus estudios en la universidad, ni que la universidad deba dejar de cultivar toda aquella excelencia académica que se necesita para resolver los problemas reales que afectan a su contexto social. Significa más bien que la universidad debe encarnarse entre los pobres intelectualmente para ser ciencia de los que no tienen voz, el respaldo intelectual de los que en su realidad misma tienen la verdad y la razón, aunque sea a veces a modo de despojo, pero que no cuentan con las razones académicas que justifiquen y legitimen su verdad y su razón ${ }^{19}$.

En estos dos testimonios, descubrimos la misma preocupación por ir más allá de un espiritualismo desencarnado o de un activismo social secularista, con el fin de renovar el apostolado de la educación, tanto con la palabra como con la acción, al servicio de la Iglesia en un mundo de increencia y deinjusticia. Tenemos que estar muy agradecidos por todo lo que se ha hecho ya en este apostolado, conjugando la fidelidad a las características de 400 años de educación ignaciana y la apertura a los cambiantes signos de los tiempos. Hoy, una o dos generaciones después del Decreto 4, nos encontramos ante un mundo que tiene todavía más necesidad de la fe que obra la justicia.

17 Pedro Arrupe (1973), Alocución al X Congreso de la Confederación Europea de Asociaciones de Antiguos Alumnos de J esuitas, agosto 1973, en Hombres para los demás, Barcelona, 1989, Diafora, 159.

18 Cf. Características de la educación de la Compañía de Jesús, (1986), Madrid, Comisión Nacional de Educación S.J.

19 I. Ellacuría, S.J ., La tarea de una universidad católica, Discurso en la Universidad de Santa Clara, 12 junio 1982 véase el texto en Una universidad para el pueblo, Diakonia nํ23 (agosto-octubre 1982) 81-88. 


\section{Una composición de nuestro tiempo y lugar}

Los veinticinco años de historia que hemos vivido y que, brevemente, acabamos de repasar, nos han traído hasta el momento actual. Ignacio de Loyola empieza muchas meditaciones de los Ejercicios Espirituales con una composición de lugar, un ejercicio de imaginación para situar la oración de contemplación en circunstancias humanas concretas. Dado que este mundo es el lugar de la presencia y actividad de Dios, Ignacio piensa que podemos encontrar a Dios si nos acercamos al mundo con fe generosa y con un espíritu de discernimiento.

Encontrarse en Silicon Valley nos trae a la mente no sólo la convergencia de misión y microchip, sino también el dinamismo e incluso la posición hegemónica que caracterizan a los EEUU de hoy. En este país se ha concentrado mucho talento y una prosperidad sin precedentes, que engendran 64 nuevos millonarios cada día. Aquí se encuentran los cuarteles generales de la nueva economía que se extiende por to do el globo y está transformando los cimientos mismos de los negocios, del trabajo y de las comunicaciones. Miles de inmigrantes llegan de todas partes: empresarios de Europa, profesionales de tecnología punta del Asia Meridional, que se colocan en las empresas de servicios, pero también trabajadores de América Latina o del Sudeste Asiático que realizan el trabajo físico; en conjunto, una diversidad notable de razas, culturas y clases.

Al mismo tiempo, los EEUU luchan con las nuevas divisiones sociales agravadas por la frontera digital, entre los que tienen acceso al mundo de la tecnología y los que se quedan fuera. Este abismo, causado por diferencias de clase, raciales y económicas, tiene su raíz última en las diferencias crónicas de la calidad de educación. Aquí en el Silicon Valley, por ejemplo, florecen algunas de las universidades más destacadas en el mundo de la investigación junto a escuelas públicas donde estudiantes afro-americanos e inmigrantes abandonan masivamente sus estudios. A escala nacional, uno de cada seis niños está condenado a la ignorancia y la pobreza.

Este valle, esta nación y el mundo entero son hoy muy distintos a lo que eran hace veinticinco años. Con la caída del comunismo y el fin de la guerra fría, las políticas nacionales y aun internacionales se han eclipsado ante un capitalismo emergente sin rival ideológico. La Unión Europea atrae lentamente a los que antaño fueron rivales en el continente hacia una comunidad que es, al mismo tiempo, fortaleza. El antiguo segundo mundo lucha para reparar el daño humano y ambiental que dejaron tras sí los llamados sistemas

\section{RFS}


socialistas. Hay fábricas que se trasladan a naciones más pobres, no para distribuir riqueza y oportunidades, sino para explotar la ventaja relativa de bajos salarios y legislaciones medioambientales poco exigentes. Muchos países se hacen todavía más pobres, especialmente allí donde prevalece la corrupción y la explotación sobre la sociedad civil y donde continúan estallando conflictos violentos.

Esta composición de nuestro tiempo y lugar abarca a seis mil millones de personas con sus rostros jóvenes o viejos, unos naciendo y otros muriendo, unos blancos y muchos otros morenos, amarillos y negros 20: todos ellos, cada uno desde su singularidad individual, aspirando a vivir la vida, a usar sus talentos, a sostener a sus familias y cuidar de sus niños y ancianos, a disfrutar de la paz y la seguridad, y a construirse un mañana mejor.

Gracias a la ciencia y a la tecnología, la humanidad es hoy capaz de solucionar problemas tales como la alimentación de los hambrientos, la vivienda de los sin techo o el desarrollo de condiciones más justas de vida, pero se resiste tercamente a hacerlo. ¿Cómo es posible que una economía boyante, más próspera y globalizada que nunca, mantenga todavía a más de la mitad de la humanidad en la pobreza? La CG 32 hace con sobriedad su propio análisis y formula su juicio moral: las desigualdades y las injusticias no pueden ya ser percibidas como el resultado de un cierta fatalidad natural: se las reconoce más bien como obra del hombre y de su egoísmo... a pesar de las posibilidades abiertas por la técnica se hace más claro que el hombre no está dispuesto a pagar el precio de una sociedad más justa y más humana ${ }^{21}$.

La injusticia hunde sus raíces en un problema que es espiritual. Por eso su solución requiere una conversión espiritual del corazón de cada uno y una conversión cultural de toda la sociedad mundial, de tal manera que la humanidad, con todos los poderosos medios que tiene a su disposición, pueda ejercitar su voluntad de cambiar las estructuras de pecado que afligen a nuestro mundo. El Informe anual sobre el Desarrollo Humano de las Naciones Unidas es un reto recurrente a considerar críticamente las condiciones básicas de vida en EEUU y en las 175 restantes naciones que comparten nuestro único planeta 22 .

20 Ver Contemplación de la Encarnación: IGNACIO DE Loyola, Ejercicios Espirituales, no 101-109.

21 CG 32, D. 4, № 27, 20.

22 Programa de Naciones Unidas para el Desarrollo, Informe sobre el desarrollo humano, anual desde 1990. 
Así es el mundo en toda su complejidad, con grandes promesas globales e innumerables y trágicas traiciones. Así es el mundo en el que las instituciones de educación superior de la Compañía están llamadas a servir a la fe y a promover la justicia.

\section{Educación superior jesuita en América a favor de la fe y la justicia}

Dentro del contexto complejo de tiempo y espacio en el cual estamos y a la luz de las últimas Congregaciones Generales quiero desarrollar algunas características ideales tal como se presentan en tres dimensiones complementarias de la educación universitaria de la Compañía: qué llegan a ser nuestros estudiantes, qué hacen nuestros profesores, y cuál es el modo de proceder de nuestras universidades. Cuando hable de ideales, algunos de ellos pueden ser fáciles de alcanzar, mientras que otros se mantienen como un reto permanente: pero unos y otros sirven para orientar nuestras instituciones universitarias y, a la larga, para dotarlas de identidad. Al mismo tiempo los provinciales de EEUU han constituido recientemente un importante Comité para la Educación Superior encargado de proponer criterios para la contratación de personal, para el liderazgo y para el patrocinio de la Compañía en nuestras Universidades y Centros de Estudios Superiores ${ }^{23}$. Ojalá que estos criterios ayuden a llevar a la práctica las características ideales sobre las que ahora vamos a reflexionar juntos.

\section{A. Formación y aprendizaje}

La ideología que predomina hoy reduce el mundo humano a una jungla globalizada, cuya ley primordial es la supervivencia de los más preparados. Los estudiantes que comparten esta visión desean verse equipados a la última en lo profesional y en lo técnico para poder competir así en el mercado y asegurarse uno de los relativamente escasos y disponibles puestos de trabajo que puedan satisfacer sus aspiraciones y resultarles lucrativos. Éste es el éxito que esperan muchos estudiantes ( iy padres!).

23 En febrero de 2000, la Conferencia J esuita (EEUU) formó una Comisión para la Educación Superior de cinco personas que preparasen propuestas con respecto: 1) patrocinio por parte de la Compañía de Jesús de EEUU de centros universitarios; 2) destino de personal a esas instituciones; 3 ) selección de Presidentes para estas instituciones (especialmente de Presidentes no jesuitas).

\section{RFS}


Todas las universidades americanas, incluidas las nuestras, están sometidas a una presión tremenda para optar decididamente por un éxito así entendido. Ahora bien, lo que nuestros estudiantes desean -y merecencomprende este éxito mundano que gira sobre las habilidades propias del mercado, pero va más allá. El criterio real de evaluación de nuestras universidades jesuitas radica en lo que nuestros estudiantes Ileguen a ser.

Durante 450 años, la educación jesuita ha buscado educar a toda la persona, a la persona completa, tanto intelectual y profesionalmente, como psicológica, moral y espiritualmente. Pero en este mundo globalizado emergente, con sus inmensas posibilidades y sus profundas contradicciones, la persona completa se entiende de modo diferente a como se entendía en la contrarreforma, en la revolución industrial o en el siglo XX. Y la persona completa del mañana no podrá ser completa sin una conciencia instruida de la sociedad y de la cultura, con la que contribuir generosamente en el mundo tal cual es. La persona completa del mañana debe tener, por resumirlo, una solidaridad bien informada.

Por esta razón debemos elevar nuestro nivel educativo jesuita hasta educar a la persona completa en la solidaridad para con el mundo real. La solidaridad se aprende a través del contacto más que de nociones, como nos recordaba recientemente el Santo Padre en un mensaje a una universidad italiana ${ }^{24}$. Cuando la experiencia directa toca al corazón, la mente se puede sentir desafiada a cambiar. La implicación personal en el sufrimiento inocente, en la injusticia que otros sufren, es el catalizador para la solidaridad que abre el camino a la búsqueda intelectual y a la reflexión moral.

Los estudiantes a lo largo de su formación, tienen que dejar entrar en sus vidas la realidad perturbadora de este mundo, de tal manera que aprendan a sentirlo, a pensarlo críticamente, a responder a sus sufrimientos y a comprometerse con él de forma constructiva. Tendrían que aprender a percibir, pensar, juzgar, elegir y actuar en favor de los derechos de los demás, especialmente de los menos aventajados y de los oprimidos. La pastoral universitaria tiene mucho que hacer para fomentar tal compasión inteligente, responsable y activa, que es la única compasión que merece el nombre de solidaridad.

Nuestras universidades se glorían también de una espléndida variedad de

24 Juan Pablo II, Mensaje a la Universidad Católica del Sagrado Corazón, Milán, 5 mayo 2000, nㅇ⒐ 
programas de actividades complementarias en las que el estudiante presta un servicio, de programas de extensión y de inserción, de contactos más allá del campus y de cursos prácticos. Todo esto no debería ser sólo algo opcional o periférico, sino quedar incluido en el núcleo mismo del programa de estudios de toda universidad de la Compañía.

Nuestros estudiantes se implican en to do tipo de acción social-ayuda a los que fracasan en la escuela, la manifestación en Seattle, servicio en comedores para pobres, promoción del derecho a la vida, protestas contra la Escuela de las Américas-, y de todo ello nos sentimos orgullosos. Pero el auténtico criterio para evaluar las universidades de la Compañía no es lo que nuestros estudiantes hagan, sino lo que acaben siendo y la responsabilidad cristiana adulta con la cual trabajen en el futuro en favor de sus prójimos y de su mundo. Las actividades en las cuales se comprometen en el presente, por muy buenos que sean sus efectos, serán siempre actividades para su formación. Esto no convierte a una universidad en un campo de entrenamiento para activistas sociales. Más bien lo que los estudiantes necesitan ahora es un compromiso cercano con el pobre y el marginado, para aprender de la realidad y llegar un día a ser adultos en solidaridad.

\section{B. Investigación y enseñanza}

Si el criterio de evaluación y el proyecto de nuestras universidades radica en lo quelleguen a ser sus estudiantes, es claro que el profesorado está en el corazón de dichas instituciones. Su misión es buscar incansablemente la verdad y hacer de cada estudiante una persona completa y solidaria para tomar sobre sí la responsabilidad del mundo real. ¿Qué es lo que los profesores necesitan para realizar esta vocación esencial?

La investigación realizada por el profesorado, que debe ser rigurosa en su racionalidad, firmemente enraizada en la fe y abierta al diálogo con todos los hombres de buena voluntad ${ }^{25}$, no sólo ha de atenerse a los cánones de cada disciplina, sino adentrarse en lo más profundo de la realidad humana, para ayudar a hacer del mundo un lugar más habitable para los 6.000 millones que vivimos en él. Quiero dejar claro que todo el conocimiento que se adquiere en la universidad es valioso en sí mismo, pero es además un conocimiento que tiene que preguntarse a sí mismo,

25 Ibid., n으. 
en favor de quién y en favor de qué está ${ }^{26}$.

Normalmente solemos hablar de los profesores en plural, pero lo que está en juego es más que la suma de los compromisos y esfuerzos personales de muchos individuos: es un diálogo interdisciplinar sostenido de investigación y reflexión, un continuo poner en común los conocimientos de todos. Su intención es asimilar las experiencias y las intuiciones de las diferentes disciplinas en una visión del conocimiento que, muy consciente de sus limitaciones, no se satisfaga con los fragmentos, sino que intente integrarlos dentro de una síntesis sabia y verdadera ${ }^{27}$ de la realidad de nuestro mundo. Desgraciadamente muchos profesores no se sienten todavía, académica, humana y, me atrevería a decir, espiritualmente, preparados para un intercambio de tal envergadura.

En algunas disciplinas, como las ciencias del hombre, las ciencias sociales, el derecho, la economía o la medicina, las conexiones con nuestro tiempo y lugar pueden parecer más obvias. Sus profesores aplican su especialización en tales materias a temas de justicia e injusticia cuando investigan o enseñan sobre la asistencia médica, la asistencia legal, la política pública y las relaciones internacionales. Pero cada campo o rama del saber tiene valores que defender, tiene repercusiones éticas. Cada disciplina, más allá de su necesaria especialización, tiene que comprometerse de forma adecuada con la sociedad, con la vida humana, con el ambiente, teniendo siempre como preocupación moral de fondo cómo deberían ser los hombres para poder vivir juntos.

Todos los profesores, a pesar del cliché de torre de marfil, están en contacto con el mundo. Pero ningún punto de vista es neutro o prescinde de los valores. En nuestro caso de jesuitas, el punto de vista, por preferencia y por opción, es el de los pobres. Por eso el compromiso de nuestros profesores con la fe y la justicia conlleva un desplazamiento significativo del punto de vista y de los valores elegidos. Al adoptar la perspectiva de las víctimas de la injusticia, nuestros enseñantes buscan la verdad y comparten esa búsqueda y sus resultados con nuestros estudiantes. Una pregunta legítima para cada uno de los profesores, aunque no resulte académica, sería: cuando investigo y enseño, ¿dónde y con quién está mi corazón? Esperar que nuestros profesores hagan una opción tan explícita y hablen sobre ella, no es nada fácil

26 Cf. CG 34, D. 17, no 6.

27 J UAN PABLo II I.C., $n$ 으. 
y tiene sus riesgos. Pero estoy firmemente convencido de que esto es lo que los educadores jesuitas han proclamado públicamente, tanto en la Iglesia como en la sociedad, como el compromiso que nos identifica.

Para asegurar que las necesidades reales de los pobres encuentran su sitio en la investigación, los profesores precisan de una colaboración orgánica con aquellos que, en la Iglesia y en la sociedad, trabajan entre los pobres y en favor de ellos, buscando activamente la justicia. Deberían implicarse con ellos en todos los aspectos: presencia entre los pobres, diseño de la investigación, recogida de datos, profundización en los problemas, planificación y acción, ejecución de la evaluación y reflexión teológica. En cada Provincia de la Compañía donde existen universidades nuestras, habría que dar prioridad a las relaciones de trabajo del profesorado con los proyectos del apostolado social jesuita -en temas como pobreza y exclusión, vivienda, SIDA, ecología y deuda del Tercer Mundo- y con el Servicio J esuita de Refugiados (J RS), que ayuda a los refugiados y a los desplazados por la fuerza.

Del mismo modo que los estudiantes tienen necesidad del pobre para aprender, los profesores necesitan compartir con el apostolado social para investigar, enseñar y formar. Tales lazos no convierten a las universidades de la Compañía en sucursales de los ministerios sociales o en instancias de cambio social, como cierta retórica del pasado llevó a algunos a temer. Son, más bien, como una garantía verificable de la opción del profesorado y una ayuda real para, como se dice coloquialmente, jestar siempre en la brecha!

Si los profesores adoptan perspectivas incompatibles con la justicia del Evangelio y consideran que la investigación, la docencia y el aprendizaje pueden ser separadas de la responsabilidad moral y de sus repercusiones sociales, están trasmitiendo un mensaje a sus estudiantes: les están diciendo que pueden desarrollar sus profesiones y sus propios intereses sin referencia alguna a ningún "otro" fuera de ellos mismos.

Por el contrario, cuando los profesores optan por el diálogo interdisciplinar y por la investigación socialmente comprometida en colaboración con las plataformas del apostolado social, están ejemplificando y modelando un tipo de conocimiento que es servicio. Y eso es lo que aprenden los estudiantes imitándolos en cuanto maestros de vida y de compromiso moral ${ }^{28}$, como dijo el Santo Padre.

28 Juan Pablo II, Discurso a la Facultad de Medicina de la Universidad Católica, Roma, 28 junio $1984, \mathrm{n} 04$. 


\section{Nuestro modo de proceder}

Si el auténtico criterio de evaluación de nuestras universidades consiste en lo que los estudiantes lleguen a ser, y si el profesorado es el corazón de todo ello, ¿qué nos queda por decir? Quizá sea este tercer punto, el carácter de nuestras universidades -cómo funcionan internamente y qué impacto tienen en la sociedad- el más difícil.

Nos hemos detenido ya en la importancia de la formación y del aprendizaje, de la investigación y de la enseñanza. La acción social que emprenden los estudiantes y el trabajo relevante desde el punto de vista social que los profesores realizan, son vitalmente importantes y necesarios, pero no dan cuenta cabal del carácter de una universidad de la Compañía, ni agotan su compromiso con la fe y la justicia, ni cumplen del todo con sus responsabilidades para con la sociedad.

¿Qué es pues lo que constituye este carácter ideal? ¿Y qué es lo que contribuye a su percepción pública? Tratándose de la universidad de la Compañía, este carácter tiene que ser la misión, que ha sido definida por la CG 32 y reafirmada por la CG 34: la diakonia fidei y la promoción de la justicia como el modo de proceder y de servir a la sociedad característicos de una universidad de la Compañía.

En palabras de la CG 34, una universidad de la Compañía tiene que ser fiel, al mismo tiempo al sustantivo universidad y al adjetivo jesuita. Por ser universidad se le pide dedicación a la investigación, a la enseñanza y a los diversos servicios derivados de su misión cultural. El adjetivo 'jesuita' requiere de la universidad armonía con las exigencias del servicio de la fe y promoción de la justicia establecidas por la CG 32, Decreto $4{ }^{29}$.

El primer modo en el que históricamente empezaron nuestras universidades a llevar a cabo su compromiso con la fe y la justicia fue a través de sus políticas de admisión, de su acción de apoyo a las minorías y de sus becas para estudiantes en desventaja ${ }^{30}$. Todos estos siguen siendo instrumentos eficaces. Una expresión todavía más elocuente de la naturaleza de la universidad de la Compañía radica en las políticas de contratación y nombramiento de profesores. Como universidad, es necesario que respete las normas

29 CG 34, D. 17, nn. 6, 7.

30 (Las universidades) sirven como cauces singulares para el progreso social de las clases pobres (CG 34, D. 17, nㅇ) 2). 
establecidas en lo académico, en lo profesional y en lo laboral; pero, como jesuita, le es esencial ir más allá de ellas y encontrar los modos de atraer, contratar y promover a aquellos que comparten activamente la misión.

Pienso que hemos hecho esfuerzos considerables y laudables para profundizar e ir más allá en lo jesuítico: hemos tratado de incidir con nuestra espiritualidad ignaciana, nuestra capacidad de reflexionar y nuestros recursos internacionales. Algunos buenos resultados son evidentes, como por ejemplo el decreto La Compañía y la vida universitaria de la última CG, y esta misma Conferencia sobre el compromiso con la justicia en la educación superior de la Compañía; y se pueden esperar también buenos resultados de la Comisión mencionada que está trabajando sobre los criterios de la Compañía en la educación superior.

Parafraseando a Ignacio Ellacuría, pertenece a la naturaleza de toda universidad ser una fuerza social, y es nuestra particular vocación como universidad de la Compañía asumir conscientemente esa responsabilidad para convertirnos en una fuerza en favor de la fe y de la justicia. Todo centro jesuita de enseñanza superior está llamado a vivir dentro de una realidad social (la que vimos en la composición de nuestro tiempo y lugar) y a vivir para tal realidad social, a iluminarla con la inteligencia universitaria, a emplear todo el peso de la universidad para transformarla ${ }^{31}$. Así pues, las universidades de la Compañía tienen razones más fuertes y distintas a las de otras instituciones académicas o de investigación para dirigirse al mundo actual, tan instalado en la injusticia, y para ayudar a rehacerlo a la luz del Evangelio.

\section{Para concluir, una agenda}

El veinticinco aniversario de la CG 32 es motivo de grande agradecimiento.

Damos gracias por la conciencia que tenemos, como universidad de la Compañía, del mundo en su totalidad y en su profundidad última:creado y sin embargo expoliado, pecador y sin embargo redimido. Asumimos nuestra responsabilidad de universidad de la Compañía para con una sociedad tan escandalosamente injusta, tan compleja de entender y tan resistente al

31 La Universidad es una realidad social y una fuerza social, marcada históricamente por lo que es la sociedad en la que vive y destinada a iluminar y transformar, como fuerza social que es, esa realidad en la que vive y para la que debe vivir. I. ElLacuría, I.c. 
cambio. Con la ayuda de otros, especialmente de los pobres, queremos desempeñar nuestro papel en la sociedad como estudiantes, como profesores e investigadores, como universidad de la Compañía.

En cuanto educación jesuita superior hacemos nuestras las nuevas maneras de aprender y de ser formados en la búsqueda de una solidaridad adulta, los nuevos méto dos de investigación y de enseñanza dentro de una comunidad académica de diálogo, y una nueva manera universitaria de practicar la fe y la justicia en la sociedad.

Al asumir nuestras características de universidad de la Compañía en este nuevo siglo, lo hacemos con seriedad y esperanza. Porque esta misma misión ha producido mártires que muestran cómo una institución de enseñanza superior y de investigación puede convertirse en un instrumento de justicia en nombre del Evangelio ${ }^{32}$. Pero llevar a cabo el Decreto 4 no es algo que una universidad de la Compañía pueda hacerlo de una vez por todas. Es más bien un ideal a mantener asumiéndolo y trabajándolo, un conjunto de características a mantener profundizándolas y llevándolas a la práctica, una conversión a mantener la oración.

El Papa J uan Pablo II en la Ex Corde Ecclesiae encomienda a las universidades católicas, con una agenda que nos reta en la enseñanza, en la investigación y en el servicio: la dignidad de la vida humana, la promoción de justicia para todos, la calidad de vida personal y familiar, la protección de la naturaleza, la búsqueda de la paz y de la estabilidad política, una distribución más equitativa de los recursos del mundo y un nuevo ordenamiento económico y político que sirva mejor a la comunidad humana a nivel nacional e internacional ${ }^{33}$. Todos estos son, al mismo tiempo, ideales muy al tos y tareas concretas. Animo a nuestros centros universitarios jesuitas a que los asuman con una comprensión crítica y con un profundo convencimiento, con una fe ardiente y con mucha esperanza en estos primeros años del nuevo siglo.

Las bellas palabras de la CG 32 nos muestran un largo sendero a seguir: el camino hacia la fe y hacia la justicia son inseparables. Y es por este camino único, por este camino empinado por el que la Iglesia peregrina -la Compañía

32 Peter-Hans Kolvenbach (1990), Discurso de statu Societatis a la Congregación de Provinciales, 20 septiembre, Acta Romana XX, 452.

33 Ex Corde Ecclesiae, (1990), 15 agosto, no 32. 
de J esús, la Universidad y el Centro de Estudios Superiores de la Compañíatiene que marchar afanosamente. Fe y justicia son inseparables en el Evangelio que enseña que 'la fe hace sentir su poder a través del amor' ${ }^{34}$. No pueden, pues, estar separadas en nuestro proyecto, en nuestra acción y en nuestra vida ${ }^{35}$. Para la mayor gloria de Dios.

Muchísimas gracias.

34 Gal 5,6.

35 CG 32, D. 2, ำ 8. 